\title{
El sino trágico de un campamento minero: Morococha
}

\author{
Heraclio Bonilla Mayta \\ Universidad Nacional de Colombia, Bogotá, Colombia \\ hbonillam@unal.edu.co
}

\begin{abstract}
RESUMEN
El presente artículo revisa la trayectoria trágica del campamento minero Morococha, a través de una exploración histórica del proceso de formación del complejo minero, asimismo, se describen las condiciones de vida de su población, que quedaron atrapados entre una Morococha Vieja en escombros y una Morococha Nueva convertida en un pueblo fantasma. Se trata pues, como la crónica de una muerte anunciada, que se reproduce una y otra vez en varios contextos del espacio nacional, como el sino o el destino de todo centro minero. Situación que se replica en la actualidad, porque quienes manejan las políticas económicas asumen que la prosperidad del país radica en la explotación eficiente de sus ventajas comparativas, basada en la explotación de sus minerales.
\end{abstract}

Palabras clave: Complejo minero, Cerro de Pasco Copper Corporation, obreros, campamento minero, Morococha

\section{The tragic destiny of a mining camp: Morococha}

\begin{abstract}
This article reviews the tragic trajectory of Morococha mining site, through a historical exploration of the formation process of the mining complex. Likewise, it describes the living conditions of its population that remained trapped between an old Morococha city in ruins and the new Morococha, turned into a ghost town. It is, therefore, as the chronicle of a death foretold, that is reproduced over and over again in various contexts of the national space, such as the destiny or the fate of every mining center. This situation is reflected in the current days, due to people who manage economic policies, and assume that the prosperity of one country lies in the efficient exploitation of its comparative advantages, based on the exploitation of its minerals.
\end{abstract}

Keywords: Mining complex, Cerro de Pasco Copper Corporation, workers, mining site, Morococha 


\section{Morococha}

Cualquier viajero que se desplaza por la carretera central de Lima a Huancayo luego de tres horas de viaje llega a un centro poblado en escombros y más adelante se encuentra con un conjunto colorido de viviendas vistosas en medio de dos lagunas y cerca de otro poblado que antaño fue la residencia de los ejecutivos norteamericanos de la Cerro de Pasco Copper Corporation, la empresa que explotaba los yacimientos de cobre. Ese cambio en el paisaje es relativamente reciente y no corresponde a los recuerdos y las vivencias que conservo. Viví en Morococha toda mi niñez y parte de mi juventud, porque mi padre trabajó cerca de tres décadas, primero como obrero minero y luego como empleado de esa empresa minera. Dejé ese campamento al jubilarse mi progenitor y al tener que empezar mis estudios en la Universidad Nacional de San Marcos en 1959. Regresé por breve tiempo en 1973 para reunir materiales que fueron publicados en 1973 en un pequeño libro titulado El minero de los Andes, pero mis obligaciones académicas impidieron, muy a mi pesar, visitar a los amigos y volver a recorrer los senderos de mi nostalgia.

La Morococha que viví era uno de esos tantos pueblos cuyo nacimiento y eclipse está asociado al descubrimiento de minerales que como el cobre o el zinc tienen una alta demanda en el mercado internacional, y cuya extracción del subsuelo y su tratamiento en los hornos de fundición requerían el desplazamiento de contingentes importantes de trabajadores del entorno. Solos, o con sus mujeres, los migrantes procedían mayormente de las comunidades del valle del Mantaro: eran campesinos, quienes buscaban enrolarse temporalmente en las actividades mineras para satisfacer necesidades complementarias, o para financiar gastos suntuarios como «mayordomos» de fiestas religiosas o "padrinos» del cortamontes en los carnavales de sus pueblos. Durante mucho tiempo eran medio obreros y medio campesinos, transicionalidad que representaba una dificultad seria para una actividad que requería un compromiso laboral a tiempo completo. $\mathrm{Ni}$ la señal nueva del salario monetario, ni el «enganche», pudieron doblegar esta obstinación, fortalecida por el orgullo de ser independientes y porque no existía, por lo menos en Morococha, nada similar a una «servidumbre crediticia».

Para cualquier turista, el paisaje de ese centro minero, sus imponentes montañas nevadas, sus lagunas contaminadas, los cerros negros de La Oroya y los campos desolados del entorno por los efectos nocivos de sus hornos, era la sucursal del infierno, inimaginable para vivir, crear amistades, compartir alegrías. Para esas mentes ajenas, era la expresión bíblica del trabajo como castigo. Y tal vez no les faltaba razón. No recuerdo las innumerables veces que tuve que pronunciar discursos cada vez que un minero fallecía por el derrumbe en el interior de una mina, o presenciar el dolor producido por la amputación de un brazo o de una pierna luego de un accidente. Pero eran gajes del oficio, sobrellevados con coraje y con dignidad. La solidaridad en la desgracia, los 
designios cambiantes del «muqui» que habitaba en el fondo de las minas, la convicción que su trabajo era el sustento de sus familias y una forma de ayuda para sus pueblos, ayudaban a vencer estos infortunios y los alentaba a continuar.

La morfología de Morococha como centro poblado era muy peculiar. Estaba dividida en dos secciones: Morococha Nueva y Morococha Vieja. La última, hacia la salida a Puquio Cocha, albergaba los centros comerciales, los restaurantes, y las ferias semanales de comestibles, además de la única escuela primaria de varones, la 1006. También el hospital, atendido por médicos norteamericanos, al igual que el más especializado de Mahr Tunnel, cerca de La Oroya. También la célebre «Mercantil», tienda de abarrotes importados que despertaba la curiosidad y el anhelo de poseer cosas nuevas. La Morococha Nueva, en cambio, era el lugar donde estaban ubicados la Alcaldía, la glorieta con su plaza, la farmacia Vidal, el local del cine, la capilla, y el taller de Sebastián Rodríguez, el fotógrafo de Morococha. También albergaba la escuela primaria de mujeres, la 1007, y la librería Loyola, donde regularmente leía El Mundo Infantil y Billiken, iniciando de esta manera mi devoción por Evita Perón, en los Andes a cuatro mil quinientos metros de altura. El Casino, el camal, un mercado, los telégrafos y más arriba la estación del ferrocarril, también hacían parte de ese escenario. Comerciantes, funcionarios públicos, propietarios o administradores de servicios, maestros de escuela, policías, era esa su población. ¿Y los obreros y los empleados de la Cerro de Pasco Copper Corporation?

Mucha gente piensa que los obreros hacen parte de un grupo homogéneo, que su condición los pone al abrigo de fisuras internas. Solidaridad sólo en el dolor, pero ni siquiera en el combate contra la patronal. Para empezar, una tajante división entre obreros y empleados, traducida en niveles diferentes de ingreso y de vivienda, era la primera expresión de una brecha insalvable. También, no todos los obreros estaban sindicalizados, y la presencia de los «amarillos» era lejos de ser insignificante. Ni los obreros ni los empleados habían llegado al mismo tiempo, de manera que una diferencia sutil se establecía entre los antiguos y los nuevos, entre los trabajadores permanentes y los temporales. Que gran parte de ellos procedían del Valle del Mantaro, una región mestiza por excelencia, evitó discriminaciones raciales, pero no su fragmentación en torno a sus pueblos o comunidades de origen. Siendo los monolingües quechuas y los analfabetos una minoría, la jerarquía entre los obreros era una función de su destreza en el trabajo, derivada de una mayor permanencia, expresada, como dije, en remuneraciones y viviendas diferentes. Solo una estabilidad laboral significativa, la vinculación directa con la empresa y la inexistencia de mecanismos de terciarización, además de reglas de promoción acatadas y de reconocimientos y recompensas por el desempeńo, explican esta situación. Cuando Centromin Perú reemplazó a la Cerro de Pasco las cosas empezaron a cambiar, porque el desempeño de los técnicos y funcionarios nacionales eran diferentes a los norteamericanos anteriores. 
Obreros y empleados vivían en diferentes campamentos, como "María», "Natividad», en casas construidas por la Cerro de Pasco, dotadas de agua y luz, con sus esposas e hijos si los tenían. Ocho horas de trabajo, como era la norma, interrumpidas por el almuerzo aportado por sus mujeres en "portaviandas», y en algunos casos, sobre todo con los empleados, con el tiempo suficiente para desplazarse hasta sus viviendas y almorzar con su familia. Esta jornada laboral permitía a algunos socializar con otros al término de la misma, además de contar con los domingos para actividades religiosas o deportivas.

¿Estaban orgullosos de su condición obrera, como suele predicar la retórica izquierdista? Ninguno compartía esa fantasía, porque no querían que sus hijos fueran como ellos, sino que avanzaran a través de la educación. Pero tampoco consideraban que su destino era una maldición sin atenuantes. Sus ingresos estaban por encima de lo pagado en la región, podían ahorrar porque muchas veces contaban con el subsidio de las economías campesinas de dónde venían, además que esa experiencia laboral, por nueva, expandía sus horizontes sociales y políticos. El trabajo rutinario, además, estaba cortado por fiestas frecuentes: bautizos, matrimonios, onomásticos, cortamontes, partidos de football y de voleyball, elecciones en el Casino, procesiones como la del Señor de los Milagros, promociones en el trabajo, juegos de tejo, de billar, o a la caza en los cerros aledaños de las vizcachas, las francolinas o a recoger el «kushuro» y atrapar las ranas de las lagunas vecinas para variar el menú cotidiano de la familia. Incluso, con ocasión de las fiestas patrias, se asistía con fervor a los desfiles de los colegios, a los paseos de antorchas, a los espectáculos circenses, o a aplaudir a Adolfo Rojas «El Nene» o a Rodolfo Forero «El Gitano», célebres toreros limeńos quienes con valentía lidiaban toros en alturas que ni «Manolete» hubiera imaginado, acompañados de solemnes bandas de músicos que interpretaban los paso-dobles para la ocasión. ¿Pudo constituirse, entonces, una identidad local, Morocochana, o era un espacio de trabajo que concluía luego de un cierto tiempo? Sin duda entre los residentes de la Morococha vieja, y tal vez entre los obreros y los empleados más estables existió un sentido de pertenencia, después de todo había un equipo de football y otro de vóley que defendían los colores del pueblo, así como grupos de guitarristas que evocaban la nostalgia por el terruño dejado, y la resignación, porque era pasajera, de la nueva vida Para la mayoría, la actividad minera concluía luego de un cierto tiempo, no habían roto los lazos con sus pueblos y era ahí donde aspiraban retornar. Se iban, venían otros que lo reemplazaban, y el ciclo se reproducía.

\section{El proceso de formación del complejo minero}

La actividad minera la realizan los hombres, las mujeres y, en ocasiones, los niños. Pero esa actividad requiere para ser ejecutada, materias primas, en este caso los metales, que 
deben ser extraídos de los socavones más profundos para ser tratados en las fundiciones de la superficie. Pero desde hace siglos esos metales no son libres, y no se puede acceder a su explotación mediante un simple «denuncio». En principio, pero solo en principio, pertenecen al «Estado», o a quienes lo controlan, quienes conceden estos recursos a terceros, vendiéndolos, arrendándolos, o percibiendo un canon por conceder el derecho a su explotación. La propiedad o el control de estos recursos ha venido variando en Morococha desde el lejano período colonial hasta el presente. En la colonia eran espańoles o criollos quienes explotaban metales preciosos mediante el pago de una regalía a la Corona, el famoso «quinto» o diezmo; en el siglo XIX eran nacionales y, sobre todo, extranjeros o sus descendientes quienes reconocían el papel fundamental del cobre en el despliegue de la «segunda» revolución industrial, es decir contaban con el conocimiento y los recursos monetarios para lanzarse en esta aventura. Pero el papel de estos pioneros no duraría mucho, porque en Morococha, al igual que en la sierra central, y en otras regiones del país, luego de la guerra con Chile, entre 1879 y 1884, los recursos naturales de la agricultura y la minería fueron no solo monopolizados sino que el capital nacional y sus agentes fueron desalojados como consecuencia de la penetración del capital extranjero, particularmente norteamericano. En la sierra central cerca de una centena de pequeños y medianos propietarios mineros se resignaron a perder sus minas, las cuales fueron absorbidas de un golpe en 1903 por ese gigante que fue la Cerro de Pasco Copper Corporation. La epopeya y sus consecuencias fueron descrita y analizada por Víctor Raúl Haya de la Torre y por José Carlos Mariátegui y fue continuada, con pasión, por sus discípulos agrupados en el APRA y en el Partido Comunista. Se iniciaba lo que Lenín llamaría la fase imperialista, la última de la expansión del capital, aunque Haya tuvo la clarividencia de advertir que en el caso del Perú no se trataba de la última sino de la primera, en un mosaico viviente donde todas las expresiones de las diferentes etapas tecnológicas de la humanidad co-existían en simultáneo, desde la "chaquitaclla» hasta el tractor. Para Mariátegui, más crudo, esa indefinición permanente, querer ser sin serlo, justificaba que el país fuera como la malagua, molusco gelatinoso, sin consistencia $\mathrm{y} \sin$ firmeza.

No se sabe nada sobre el pasado colonial de Morococha, salvo anécdotas intrascendentes. La información es más confiable sólo desde mediados del siglo XIX. Fabio Domayre Miranda (2016) informa que la molienda de metales en Tucto de propiedad del terrateniente Martín de Bidegaray, fue continuada por Francisco de Izcue en 1840, quien al quebrar su negocio se asoció con el alemán Carlos Pflücker para formar la Compañía Peruana de Minas de Cobre. A la muerte del primero, Pflüker continúa la explotación incluyendo a sus compatriotas Erdmann y Honigman. Cuando muere en 1885 lo suceden sus hijos Carlos María, Julio y Leonardo formando la sociedad Carlos M. Pflüker y Hermanos. Pronto aparecieron otras: Sociedad Minera Austria Duvaz fundada en 1906 por L. Proaño, la Sociedad Minera Yauli de Pedro de Osma 
en 1926; Ricardo Mahr en Mahr Tunel, la Sociedad Minera Alpamina (1889) y la de Puquiococha (1902).

Pero a comienzos del siglo XX las dificultades en la explotación de las minas obligaron a la familia Pflüker a vender sus minas a James B. Haggin y A. W. MacCune, empresarios norteamericanos, quienes formaron la Morococha Mining Co. Según reporta Miranda, de manera paralela Jacob Backus y Howard Johnston adquirían igualmente otros centros mineros del entorno, controlando ambos la producción regional hasta la aparición de la Cerro de Pasco Corporation en 1903. Con la Cerro de Pasco la explotación minera se intensifica y a la vez se tecnifica, al mismo tiempo que se impulsa la expansión del centro poblado de Morococha, la que culmina con su elevación a la categoría de Distrito con pertenencia a la provincia de Yauli por Ley 683 del 26 de octubre de 1907.

Si se piensa en Morococha en el umbral del siglo XX habría que reconocer que por primera vez empieza a configurarse un escenario enteramente inédito, el del capital y el del trabajo, y cuyos agentes serán los actores principales de un proceso social dramático y cuyos retazos empiezan a ser conocidos gracias a las investigaciones de Alberto Flores-Galindo, Dick Kruijt y Menno Vellinga, Carlos Contreras, Adrian de Wind, Julian Laite. Tal escenario no podía pasar desapercibido para las fuerzas políticas igualmente emergentes en el Perú, para sus principales líderes como José Carlos Mariátegui, Ricardo Martínez de la Torre, Abelardo Solís, desde el socialismo, y Víctor Raúl Haya de la Torre desde la vertiente que sería más tarde el Apra. Mariátegui se preocupó para que sus revistas, Amauta y Labor se difundieran en Morococha e incluso envió a ese lugar al dirigente textil Julio Portocarrero, en virtud de los contactos con la colonia italiana, en particular con Carlos Pezzuti, dueño de una librería (Mazzi Huaycucho, 2017), a fin de organizar un sindicato con el concurso de Gamaniel Blanco, maestro de escuela, y Adrián Sovero, obrero minero. Se buscaba crear una organización que fuera más allá del sindicalismo local, una Federación de Trabajadores Mineros que incluyese a todos los trabajadores de la sierra central. Esa articulación permitió que se difundiera catástrofes como la muerte de 32 obreros cuando se inundó la galera «María Elvira» con las aguas de la laguna Morococha, y se tradujo también, según reporta Mazzi Huaycucho, en el papel activo que tuvo Mariátegui en la huelga de los mineros del 10 de octubre de 1929 en protesta por el despido de medio centenar de trabajadores y la reducción del sueldo de los lamperos de la mina. Pero el impacto de Mariátegui no se limitó a la protesta y a la organización, sino en la aparición, según documenta Mazzi Huaycucho , de revistas como Correo de Morococha (1916-1917), Luminarias (1924), Claridad (1928), Social(1929), Alborada (1929) de Gamaniel Blanco y César Augusto Palacios, y Justicia (1930), también de Blanco y quien además publicó en ese año Apuntes monográficos de Morococha, e incluso, desde la orilla opuesta, La Voz de Morococha (1925-1929), dirigi- 
da por Antonio Pasquale, representante del leguiismo y parcialmente financiada por la empresa Cerro de Pasco Copper Corporation.

Y si bien estos esfuerzos por respaldar la protestas legítimas de los obreros mineros, y ayudarlos en la construcción de organizaciones más efectivas y potentes eran importantes, con todo subsiste el dilema de saber cómo lo hicieron, cómo articularon un lenguaje y un mensaje cuya cantera era profundamente eurocéntrica, en un contexto de protagonistas medio obrero y medio campesinos, con un horizonte de conciencia que mezclaba nociones nuevas de opresión y de justicia con imágenes como la de los «tíos» y de los «muquis», en el marco de una realidad que no era enteramente occidental y que seguía anclada en una racionalidad distinta y opuesta. ¿Cuál fue el contenido de esa nueva conciencia social, en el caso que ella lograra formarse y consolidarse?

\section{El derrumbe}

El sino o el destino de todo centro minero, de sus viviendas, de su población o de sus recursos, es estar estrechamente asociado a la cantidad y calidad de las vetas de minerales sobre los que están asentados. Surgen y desaparecen en función de la disponibilidad de los minerales. O se transforman, como en el caso de Morococha, cuando nuevas prospecciones constatan que son más abundantes de las que se pensaban, y puesto que estas vetas son las únicas que importan es indispensable cambiar todo, incluso la disposición de los asentamientos con prescindencia completa de lo que pueda pasar con la suerte de la población como consecuencia de estos cambios. Es esto lo que ocurrió: la Morococha de antes y que se evoca al inicio de este texto, yace ahora en escombros, al tiempo que pocos kilómetros más adelante, en una hondonada, existe un vistoso complejo construido por la empresa que adquirió los yacimientos de cobre destinado para albergar a la población desplazada de sus antiguas viviendas. Una solución y una alternativa que en principio debiera ser satisfactoria, no lo es en cambio para esa población, quienes en gran parte abandonaron estas nuevas residencias, mientras que otros, peor aún, se aferran obstinadamente a sus antiguas casas de la Morococha vieja, sin importarles el deterioro de las mismas, la polución que contamina sus aguas, la inexistencia de servicios higiénicos adecuados, y el ruido ensordecedor de petardos de dinamita y taladros que perforan el suelo, agregando detritus, tierra y polvos adicionales. Prefieren eso a una alternativa lúgubre. En realidad, se trata de la crónica de una muerte anunciada, que se reproduce una y otra vez en varios contextos del espacio nacional, como resultado de la convicción que albergan quienes manejan las políticas económicas: la prosperidad del país radica en la explotación eficiente de sus ventajas comparativas, que desde luego se basa en la explotación de sus minerales, porque no hacerlo sería nocivo para la economía y el país. Como dijo un ex presidente, protestar contra este mandato obvio sería 
comportarse como el "perro del hortelano", que no come ni deja comer. Convicción ampliamente compartida por empresarios nacionales y extranjeros, quienes asumen la premisa del "huaquero», para quien el vulgar saqueo de los recursos históricos o naturales es sinónimo de producción, bajo el señuelo que en ese festín participan también los gobiernos nacionales, regionales y ahora locales a través de las dádivas del canon minero, con el agravante que esas autoridades ni siquiera son capaces de utilizar esos recursos porque no tienen la más mínima idea de qué hacer con los mismos, salvo evidentemente enriquecerse, ellos, sus familias y sus cómplices, como lo vienen haciendo desde los lejanos tiempos coloniales.

Vivimos un mundo cambiante, no por irónico no menos trágico. Los españoles llegaron al Perú en 1532 para "hacer la América», luego en el siglo XIX los mercaderes y hombres de negocios ingleses aparecieron en las orillas del Pacífico peruano porque requerían mercados donde vender las mercancías de sus industrias y llevarse a cambio, por increíble que parezca, el guano de las islas, y más tarde en el siglo XX fue el turno de los capitales norteamericanos para hacer inversiones y explotar los recursos mineros y agrarios, en un contexto internacional donde Rusia, desde 1917, y China, desde 1949, parecían representar alternativas al sojuzgamiento de las áreas periféricas por parte del Occidente, en concordancia con las premisas opuestas que decían animaban a sus respectivos gobiernos. Pero el «socialismo realmente existente», que era lo que había para designar esa pantomima, se desvanecía abruptamente y solo quedaba su rival, la República Popular China, para mantener en vilo la continuidad de una esperanza, al menos así lo proclamaban sus seguidores en las disputas con los «moscovitas», controversia que fue además la fuente que nutrió movimientos desde Patria Roja hasta Sendero Luminoso. Pero el poder, o su versión maquiavélica, tienen una lógica y una racionalidad que la razón no entiende. Hoy, en el Perú y en varios países de la América Latina, es esa gerontocracia china, que hasta la fecha combina bien las formas más despóticas de explotación estatal con un vigoroso mercado dada su inmensidad, es la principal inversora de capitales extranjeros, particularmente en el sector minero, y no precisamente en beneficio de los explotados del mundo, sino de quienes tienen el control del gobierno chino. Son sus agentes que desplazan cuantiosos capitales para ser invertidos en proyectos como "Toromocho», para asegurarse del control de materias primas estratégicas y no precisamente para el bienestar del proletariado mundial.

La debacle empieza en 1973 cuando el gobierno militar dirigido por el general Juan Velasco Alvarado expropió la Cerro de Pasco Copper Corporation para transferir su gestión a Centromin Perú, la cual incluía las perforaciones en "Toromocho», empresa que fue luego privatizada por el gobierno de Alejandro Toledo en el 2003. Luego, la adquirió la empresa canadiense Peru Copper mediante el pago de un millón de dólares, quien la vendió despues a la empresa estatal china Chinalco por 790 millones de dólares, sin que quedara claro cuál era la participación del Estado peruano en estos negociados. La 
empresa china Minera Chinalco Perú S.A es subsidiaria de la Aluminium Corporation of China (CHINALCO), uno de los más grandes conglomerados industriales de la República popular China. El contrato de transferencia de las concesiones y activos mineros fue firmado el 5 de mayo de 2008. Su inversión inicial fue de 4,820 millones de dólares, monto que en 2016 se amplió con 1,300 millones de dólares adicionales. En el 2017, la empresa produjo 190 mil toneladas métricas finas de cobre y esperaba aumentar con esa inversión una producción adicional de 75 mil toneladas, proeza que convertiría al país en el segundo productor mundial de cobre luego de Chile. Las reservas han sido calculadas en mil quinientos millones de toneladas de mineral, con un horizonte de cerca de treinta años de explotación, con una meta de producción de ciento veinte mil toneladas diarias. En declaraciones de la propia empresa, se llegaría a producir un millón de toneladas anuales de concentrado de cobre, diez mil toneladas de óxido de molibdeno y cuatro millones de onzas de plata, generando para la empresa dos mil cien millones de dólares como utilidades «durante la vida de la mina...».

Para que la meta se cumpliese era indispensable remover de sus lugares de residencia a cerca de mil doscientas familias, proceso que a la fecha se ha cumplido casi totalmente, salvo sesenta y cinco familias asentadas en 34 hectáreas pertenecientes a la Municipalidad distrital, convenientemente expropiadas en 2018 por la Superintendencia de Bienes Estatales (SNB), quienes rechazan su traslado a la pintoresca Nueva Morococha. Morococha, el poblado inicial, tuvo una población declinante, bajó de 13,508 a 5,397 habitantes según los censos nacionales de esos años, ubicada su población en los deciles de pobreza más acuciantes. Y en esas condiciones, no es extraño que la llegada de los capitales chinos y la apertura de Toromocho generara esperanzas y expectativas muy grandes, pero la decepción no tardó en llegar entre los que se desplazaron a Carhuacoto (Nueva Morococha) y entre quienes se quedaron en la ciudad antigua.

\section{La trayectoria del desencanto}

En 1570, el arquitecto del orden colonial que fue el virrey Francisco de Toledo inició un masivo proceso de urbanización rural, consistente en agrupar en pueblos dispersos a la población nativa que logró sobrevivir a la hecatombe de la conquista, a fin de que fuese más fácil reclutarla compulsivamente como "mitayos» en los centros mineros de Potosí y de Huancavelica, además de facilitar su catequización. Estos agrupamientos forzados rompieron las redes sociales existentes y cancelaron las identidades étnicas previas. Es seguramente el antecedente más lejano a lo ocurrido en Morococha en los años recientes, aunque el objetivo no haya sido crear un mercado cautivo de mano de obra, sino facilitar la explotación de importantes yacimientos de cobre que yacían bajo sus pies. Pero el nuevo asentamiento, Morococha Nueva, es casi un pueblo fantasma, 
abandonado por parte de sus habitantes cuyas condiciones de trabajo los condenan al aislamiento, en condiciones de estabilidad laboral extremadamente precarias por la terciarización que regula su reclutamiento. Y si bien están ahí instaladas oficinas públicas y privadas, incluso una iglesia, estas no desempeñan el papel de cohesión de antes. Ni siquiera procesiones como las del Señor de los Milagros, o de la Cruz, despiertan el entusiasmo colectivo porque sus imágenes no se desplazan en este nuevo entorno. Agrupamiento etéreo, casi fantasmal, que no propicia socialización alguna, como tampoco ofrece oportunidades de trabajo complementarias. Y para quienes se aferran en vivir en los escombros de la vieja ciudad, el desencanto de la nueva experiencia de los desplazados, la nostalgia de parajes vividos, y la exigencia de compensaciones adecuadas a cambio del abandono, son razones más que suficientes para nutrir esta resistencia, para no mencionar la abismal diferencia entre sus magros ingresos y las astronómicas ganancias de la empresa china. Morococha no es más lo que fue, y sería deseable que esta deplorable experiencia encaminara mejores decisiones en este y otros contextos.

\section{Referencias}

Donayre M., F. (2016). Politicas de lugar en Morococha: el contexto del reasentamiento por el proyecto minero Toromocho. Tesis de Licenciatura en Antropología. Pontificia Universidad Católica del Perú.

Mazzi H., V. (2017). Impacto de Amauta en la prensa minera de Morococha (1926-1930), Utopia y Praxis Latinoamericana. Universidad de Zulia, vol. 22, No. 77. 